\title{
A thermal, sorptive and spectral study of HDTMA-bentonite loaded with uranyl phosphate
}

\author{
Dariusz Sternik $^{1} \cdot$ Agnieszka Gładysz-Płaska $^{1} \cdot$ Ewelina Grabias $^{2}$ • \\ Marek Majdan ${ }^{1}$ - Waldemar Knauer ${ }^{3}$
}

Received: 7 December 2016/Accepted: 2 April 2017/Published online: 12 April 2017

(C) The Author(s) 2017. This article is an open access publication

\begin{abstract}
The influence of phosphate ions on the thermal stability of complexes obtained by adsorption of uranium(VI) on organobentonite was determined. Organoclay samples were prepared by the reaction of hexadecyltrimethylammonium bromide with bentonite. The isotherms of sorption/desorption of $\mathrm{U}(\mathrm{VI})$ from aqueous solutions containing phosphate ions onto different forms of bentonite were measured using the batch method. The highest amount of uranium was absorbed on HDTMAbentonite in the presence of phosphates. This may have been associated with the complexing of $\mathrm{U}(\mathrm{VI})$ ions by phosphate ions, which interacted with surfactant cations probably via electrostatic forces. A TG-DSC-MS study showed that the thermal decomposition of the surfactant sorbed on bentonite proceeded in two stages: at 200-400 and at $600-800{ }^{\circ} \mathrm{C}$. The first stage involved defragmentation and oxidation of surfactant cations present in the interior and on the surface of the mineral. The second stage involved oxidation of charcoal and simultaneous dehydroxylation of the sorbent. The oxidation of surfactant cations and the dehydroxylation of the mineral were suppressed in the presence of phosphates.
\end{abstract}

Keywords Organoclays · Uranium adsorption · Thermal analysis

Dariusz Sternik

dsternik@poczta.umcs.lublin.pl

1 Faculty of Chemistry, Maria Curie Skłodowska University, 3 M. Curie Skłodowska Sq., 20-031 Lublin, Poland

2 Faculty of Mathematics, Physics and Computer Science, Maria Curie Skłodowska University, 20-031 Lublin, Poland

3 NETZSCH-Gerätebau GmbH, Wittelsbacherstrasse 42, 95100 Selb, Germany

\section{Introduction}

The presence of uranium, a toxic and radioactive element, in the aqueous environment started to be a problem when nuclear power stations were introduced as an effective source of energy. Although there exist various methods for the removal of uranium from wastes, which include chemical precipitation, solvent extraction, ion exchange, ultrafiltration, reverse osmosis and nanofiltration [1-3], their use is hampered by disadvantages such as high cost, environmental pollution and ineffectiveness at low uranium concentrations. Among these methods, sorption is the one most commonly used for the recovery and removal of uranium. Different sorbents are applied for this purpose, the best known among which are clays.

An aluminum phyllosilicate clay called bentonite, which is characterized by a high sorption capacity and an ability to swell under the influence of sorbed water, has been evaluated as a good material for the construction of ecological-engineering barriers for safe storage of nuclear wastes [4]. In our earlier experiments, we assessed the sorption affinities of hexadecyltrimethylammonium-bentonite (known as HDTMA-bentonite) toward U(VI) ions $[5,6]$. We intentionally selected an organobentonite as a sorbent, bearing in mind its high affinity toward organic impurities, i.e., mainly hydrocarbons present in nuclear wastes generated from the PUREX process [7], as well as its ability to solidify organic wastes containing actinides. Sorption of U(VI) on bentonite depends on the presence of various ions, including sulfates, carbonates, arsenates and, especially, phosphates [8]. The mechanism of U(VI) sorption can be evaluated by different methods, among them the batch equilibrium method, thermal analysis and FTIR spectroscopy, which provide information on the role of the different surface groups of the mineral in the 
complexation of $\mathrm{U}(\mathrm{VI})$. We had partially explained the mechanism of U(VI) sorption in our earlier paper [9], in which de Job method had been used as a tool for the diagnosis of the stoichiometry of the surface complexes formed. In the present study, we investigated thermal degradation of sorption products to elucidate the mechanism of interaction between the surfactant and the bentonite matrix. There is relatively little research concerning thermal analysis of HDTMA-bentonite [10-17]; however, this problem has received sufficient scrutiny in the works concerning the analog of bentonite, montmorillonite [18-22]. The introduction of phosphate ions to a sorption system is a new problem, and there is a dearth of research concerning thermal analysis of HDTMA-P(V)-bentonite and its modifications with U(VI).

\section{Experimental}

\section{Materials}

The experiments were conducted using Volclay bentonite with the following chemical composition: $\mathrm{Al}_{2} \mathrm{O}_{3}-16.9 \%$, $\mathrm{SiO}_{2}-60.7 \%, \mathrm{Fe}-2.66 \%, \mathrm{Mg}-1.18 \%, \mathrm{Ca}-0.53 \%$, $\mathrm{Na}-1.73 \%, \mathrm{~K}-0.81 \%$. Hexadecyltrimethylammonium bromide (HDTMA-Br, 98\% purity) and $\mathrm{Na}_{2} \mathrm{HPO}_{4}$ (purity, min. $99 \%$ ) were used as modifiers. All materials were supplied by Sigma-Aldrich.

\section{Sorption experiments}

\section{Preparation of the sorbent}

A sodium form of bentonite, designated Na-bentonite, was prepared by equilibration of $5 \mathrm{~g}$ of Volclay bentonite with
$0.1 \mathrm{~mol} \mathrm{dm}^{-3} \mathrm{NaCl}$ (Sigma-Aldrich, 99.99\% purity) solution.

Organobentonites used in thermal and spectral analysis were prepared by equilibration of $1 \mathrm{~g}$ Na-bentonite with aqueous solutions of hexadecyltrimethylammonium bromide for $4 \mathrm{~h}$ at $60{ }^{\circ} \mathrm{C}$ in the absence and presence of $\mathrm{U}(\mathrm{VI})$ and $\mathrm{P}(\mathrm{V})$ ions in the aqueous phase (Table 1). The initial concentrations of HDTMA-Br in the aqueous phase were $0.0001,0.001$ and $0.01 \mathrm{~mol} \mathrm{dm}^{-3}$. The concentration of $\mathrm{C}$ in 2-mg samples was determined using a PerkinElmer 2400 CHN analyzer. The molar concentration of the HDTMA ${ }^{+}$ cation in the samples $\left(\mathrm{C}_{\mathrm{HDTMA}}\right.$ \% CEC $)$, corresponding to the number of $\mathrm{HDTMA}^{+}$moles per $1 \mathrm{~g}$ of the inorganic part of the samples, was calculated according to the formula [5, 23]: $C_{\mathrm{HDTMA} \% \mathrm{CEC}}=100 \cdot C_{\mathrm{m}} /\left(1-C_{\mathrm{m}} \cdot \mathrm{FW}\right) / \mathrm{CEC}$

where $C_{\mathrm{m}}$ is the molar concentration of $\mathrm{HDTMA}^{+}$in the organoclay (in mol $\mathrm{g}^{-1}$ ), $\mathrm{FW}$ refers to the formula mass of the alkylammonium cation (284.56) and CEC is the cation exchange capacity of $\mathrm{Na}$-bentonite, i.e., $0.00079 \mathrm{~mol} \mathrm{~g}^{-1}$ [5]. The obtained organobentonite samples were designated as HDTMA-, HDTMA-U(VI)-, HDTMA-U(VI)-P(V)and HDTMA-P(V)-bentonite.

Additionally, two different samples were activated by treating raw bentonite with $0.5 \mathrm{M} \mathrm{HNO}_{3}$ and heating in temperature of $250{ }^{\circ} \mathrm{C}$ in a muffle furnace for $6 \mathrm{~h}$. The acid activation was carried in a system consisting of a $100 \mathrm{mg}$ sample/ $0.1 \mathrm{dm}^{3}$ acid solution. The suspension was vigorously stirred for $4 \mathrm{~h}$ at room temperature. Then, the solid was washed several times with the redistilled water, filtered and dried. The obtained bentonite samples were designated as R-bentonite (raw bentonite), H-bentonite (acid activated bentonite) and T-bentonite (thermally activated bentonite).

Table 1 Conditions of synthesis of the analyzed organoclays

\begin{tabular}{|c|c|c|c|c|c|c|}
\hline \multirow[t]{2}{*}{ Sample } & \multicolumn{3}{|c|}{ Initial concentration of reagents $/ \mathrm{mol} \mathrm{dm}^{-3}$} & \multirow[t]{2}{*}[\mathrm{HDTMA}]{$_{\mathrm{s}} / \mathrm{mmol} \mathrm{g}^{-1}$} & \multirow{2}{*}{$\begin{array}{l}\text { Surfactant in } \\
\text { clays/vs. \%CEC }\end{array}$} & \multirow[t]{2}{*}{$\mathrm{U}(\mathrm{VI}) / \mathrm{mmol} \mathrm{g}^{-1}$} \\
\hline & {$[\text { HDTMA }]_{\text {in }}$} & {$[\mathrm{U}(\mathrm{VI})]_{\mathrm{in}}$} & {$\left[\mathrm{HPO}_{4}^{2-}\right]_{\text {in }}$} & & & \\
\hline Na-bentonite & - & - & - & & & \\
\hline \multirow[t]{3}{*}{ HDTMA-bentonite } & 0.0001 & - & - & 0.134 & 18.7 & \\
\hline & 0.001 & - & - & 0.486 & 75.7 & \\
\hline & 0.01 & - & - & 1.590 & 389.9 & \\
\hline \multirow[t]{3}{*}{ HDTMA-U(VI)-bentonite } & 0.0001 & 0.0005 & - & 0.156 & 21.9 & 0.246 \\
\hline & 0.001 & 0.0005 & - & 0.493 & 77 & 0.185 \\
\hline & 0.01 & 0.0005 & - & 1.845 & 521.5 & 0.242 \\
\hline \multirow[t]{3}{*}{ HDTMA-P(V)-bentonite } & 0.0001 & - & 0.01 & 0.313 & 46.1 & \\
\hline & 0.001 & - & 0.01 & 0.573 & 91.9 & \\
\hline & 0.01 & - & 0.01 & 1.075 & 207.8 & \\
\hline \multirow[t]{3}{*}{ HDTMA-U(VI)-P(V)-bentonite } & 0.0001 & 0.0005 & 0.01 & 0.211 & 30.1 & 0.247 \\
\hline & 0.001 & 0.0005 & 0.01 & 0.447 & 68.7 & 0.249 \\
\hline & 0.01 & 0.0005 & 0.01 & 1.081 & 209.5 & 0.25 \\
\hline
\end{tabular}




\section{Uranium(VI) and phosphate $(V)$ sorption}

Uranium(VI) and phosphate(V) sorption on bentonite was performed in a system consisting of a $100 \mathrm{mg}$ sample of sorbent $/ 0.1 \mathrm{dm}^{3}$ aqueous phase. Solutions of uranyl acetate (Lachema n.p. Brno, p.a.), $\mathrm{Na}_{2} \mathrm{HPO}_{4}$ and $\mathrm{CH}_{3} \mathrm{COONa}$ were used as the aqueous phase. The concentration of $\mathrm{UO}_{2}$ $\left(\mathrm{CH}_{3} \mathrm{COO}\right)_{2}, \mathrm{Na}_{2} \mathrm{HPO}_{4}$ and $\mathrm{CH}_{3} \mathrm{COONa}$ in the initial solutions was always $0.0005 \mathrm{~mol} \mathrm{dm}^{-3}$ [for $\mathrm{U}(\mathrm{VI})$ ], $0.01 \mathrm{~mol} \mathrm{dm}^{-3}$ (for $\mathrm{HPO}_{4}^{2-}$ ) and $0.05 \mathrm{~mol} \mathrm{dm}^{-3}$ (for $\mathrm{CH}_{3} \mathrm{COONa}$ ), respectively. The exact concentrations of $\mathrm{U}(\mathrm{VI})$ and $\mathrm{PO}_{4}^{3-}$ in the solutions were determined by the Arsenazo III method [24] and the phosphomolybdic method, respectively [24, 25]. A constant temperature $\left(23{ }^{\circ} \mathrm{C}\right)$ and shaking time $(6 \mathrm{~h})$ were maintained during all sorption experiments. A mechanical shaker was used for the equilibration of phases at 150 oscillations $\min ^{-1}$. In the final step, the solutions were filtered and centrifuged, and the concentrations of $\mathrm{U}(\mathrm{VI})$ in the equilibrium phase $\left(C_{\mathrm{eq}}\right)$ were determined. The sorption constants $K_{\mathrm{d}}$ of $\mathrm{U}(\mathrm{VI})$ ions were found from:

$K_{\mathrm{d}}=C_{\mathrm{s}} / C_{\mathrm{eq}}$

$C_{\mathrm{s}}=\left(C_{0}-C_{\mathrm{eq}}\right) V / m$

where $C_{0}, C_{\mathrm{s}}, C_{\mathrm{eq}}$ denote the concentrations of $\mathrm{U}(\mathrm{VI})$ in the initial solution, sorbent phase and equilibrium solution, whereas $V$ and $m$ refer to the volume of the aqueous phase (in $\mathrm{cm}^{3}$ ) and mass of the sample (in $\mathrm{mg}$ ), respectively.

The desorption of U(VI) was completed in the following way: After an equilibrium was achieved, the whole sorption system was left to stand for $24 \mathrm{~h}$ and then $10 \mathrm{~cm}^{3}$ of $\mathrm{H}_{2} \mathrm{O}$ was added to the aqueous phase and a new equilibrium was established during $6 \mathrm{~h}$.

\section{Methods}

\section{FTIR spectrograms}

The FTIR spectra of the samples were recorded in the transmission mode at room temperature by means of a 1725X PerkinElmer instrument using the $\mathrm{KBr}$ pellet technique (1:20) with a resolution of $2 \mathrm{~cm}^{-1}$. $\mathrm{KBr}$ was dried at $200{ }^{\circ} \mathrm{C}$ for $24 \mathrm{~h}$, after which $560 \mathrm{mg} \mathrm{KBr}$ was homogenized with a bentonite sample in a ball grinder (produced by Narva Brand-Erbisdorf, Germany). The tablets (radius $1 \mathrm{~cm}$, thickness $0.1 \mathrm{~cm}$ ) were prepared using a hydraulic press.

\section{Thermal decomposition spectra}

Thermal analysis was carried out on a STA 449 Jupiter F1 apparatus from Netzsch (Germany) under the following operational conditions: heating rate of $10 \mathrm{~K} \mathrm{~min}^{-1}$, a dynamic atmosphere of synthetic air $\left(50 \mathrm{~mL} \mathrm{~min}^{-1}\right)$, temperature range of $30-950{ }^{\circ} \mathrm{C}$, sample mass $\sim 20 \mathrm{mg}$ and sensor thermocouple type S TG-DSC. An empty $\mathrm{Al}_{2} \mathrm{O}_{3}$ crucible was used as a reference. The gaseous products emitted during the decomposition of the materials were analyzed by QMS 403D Aeölos (Germany) coupled online to the STA instrument. The QMS data were collected in a range from 10 to $150 \mathrm{amu}$. NIST library database was used for mass spectra analysis.

\section{Results and discussion}

\section{Sorption of $U(V I)$ ions on bentonite in the presence of phosphates}

A summary of data on the sorption of $\mathrm{U}(\mathrm{VI})$ on different forms of bentonite in the presence of phosphate ions is given in Fig. 1. An enhanced sorption of $\mathrm{U}(\mathrm{VI})$ on HDTMA-bentonite was observed for equilibrium concentrations higher than $0.0001 \mathrm{~mol} \mathrm{dm}^{-3}$. The remarkably lower sorption of U(VI) on H-bentonite can be explained by the high affinity of the small $\mathrm{H}^{+}$ions for bentonite and, therefore, their difficult exchange with U(VI) ions. One can conclude, based on this preliminary test of sorption, that HDTMA-bentonite is a good sorbent of $\mathrm{U}(\mathrm{VI})$ in the presence of phosphates, which is interesting from a practical point of view, since organobentonite is also a good sorbent of organic impurities, i.e., hydrocarbons and their derivatives, present in nuclear wastes.

The results of the sorption/desorption experiment are given in Fig. 2. There was an evident decrease in the sorption and desorption $\log K_{\mathrm{d}}$ constants of $\mathrm{U}(\mathrm{VI})$ with the increase in the initial concentration $C_{0}$ as a result of the free surface sorbent sites being occupied by U(VI) ions. This notwithstanding, the decrease in the $\log K_{\mathrm{d}}$ values for HDTMA-bentonite was not so sharp as that observed for the remaining bentonites. This was probably a consequence of the enhanced participation of $\mathrm{U}(\mathrm{VI})$ phosphate precipitation in the overall process of sorption, similarly to the result of our recent work [9] where have found the precipitation of $\left(\mathrm{UO}_{2}\right)_{3}\left(\mathrm{PO}_{4}\right)_{2} \cdot 4 \mathrm{H}_{2} \mathrm{O}$ in the interlamellar space of Na-bentonite. For all kinds of bentonite, with the exception of $\mathrm{H}$-bentonite, the desorption isotherms differed from the sorption isotherms, which attested to the irreversibility of the entire sorption process. Surface precipitation and surface complexation play important roles in $\mathrm{U}(\mathrm{VI})$ immobilization by bentonite [26-28].

\section{FTIR spectra of the sorption products}

Changes in vibrations of the aluminosilicate skeleton are given in Fig. 3. There is a remarkable shift of $\mathrm{Si}-\mathrm{O}-\mathrm{Si}$ and 
Fig. 1 Sorption isotherms of $\mathrm{U}(\mathrm{VI})$ ions on the different forms of bentonite $(\mathrm{R}$ - raw bentonite, $\mathrm{Na}$ - sodium form, $\mathrm{H}-$ after acid activation, $\mathrm{T}$-thermally activated, HDTMA—organoclays)

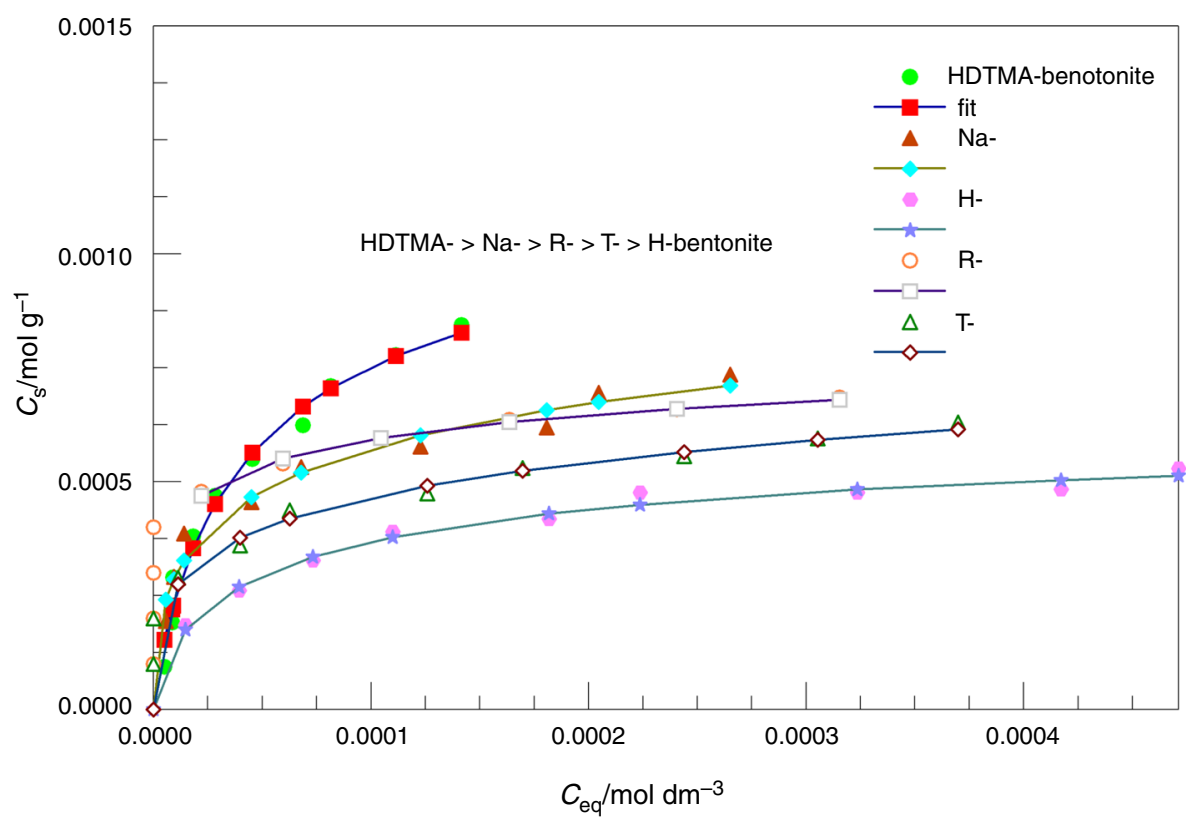

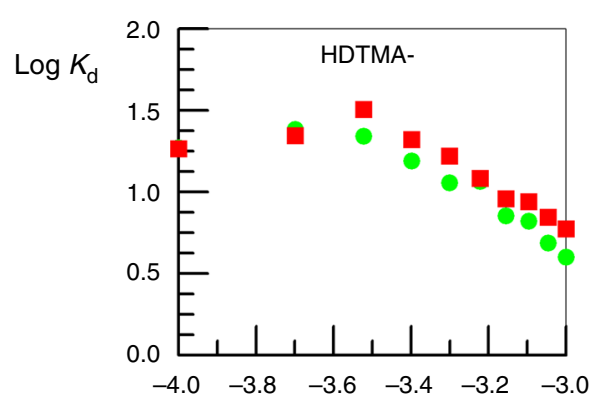

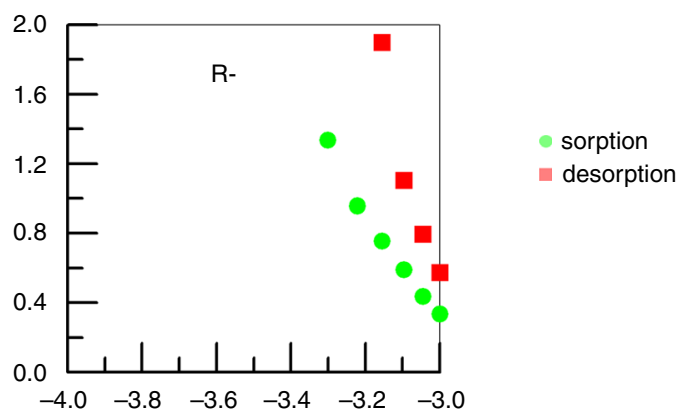

$\log c_{0}$
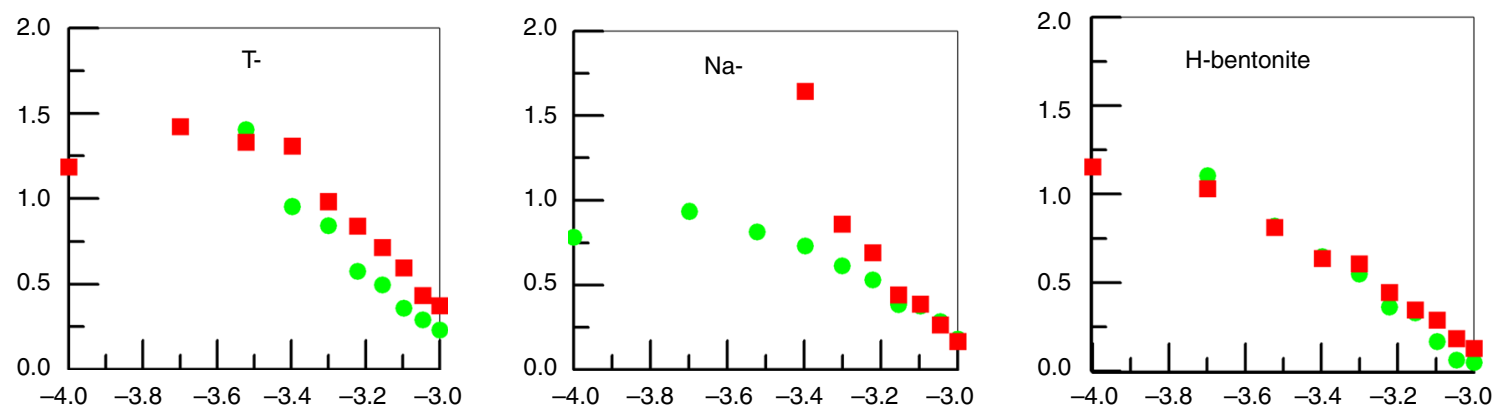

Fig. 2 Change of sorption/desorption constants $\log K_{\mathrm{d}}$ of $\mathrm{U}(\mathrm{VI})$ ions with their initial concentration $\log C_{0}$ (circles sorption, squares desorption)

Al-O-Si deformation vibrations into the higher wavelengths (from 468 to $474 \mathrm{~cm}^{-1}$ ) during the formation of HDTMA-U(VI)-P(V)-bentonite. This is probably a consequence of interaction of the U(VI) phosphate complex with oxygen atoms from $\mathrm{Si}-\mathrm{O}-\mathrm{Si}$ and $\mathrm{Al}-\mathrm{O}-\mathrm{Si}$ bridges. It is interesting that the interaction of $\mathrm{P}(\mathrm{V})$ ions with the bentonite matrix (vibration at $470 \mathrm{~cm}^{-1}$ ) is a little weaker, probably as a result of formation of a hydrogen bond with siloxane oxygens. The evident perturbation of the Al-OHAl bending vibration upon the influence of the U(VI) phosphate complex results in the shift of the band from 918 to $913 \mathrm{~cm}^{-1}$. This result is the confirmation of our earlier data [9] concerning U(VI) sorption on Na-bentonite in the presence of phosphates, when we have found evident interaction of $\mathrm{UO}_{2} \mathrm{HPO}_{4}$ complex with bentonite aluminols $\equiv \mathrm{Al}-\mathrm{OH}$. Additional proofs for the strong interaction of 
Fig. 3 FTIR spectra of bentonite. The region of bending and stretching vibrations

Fig. 4 FTIR spectra of bentonite. The region of $\mathrm{C}-\mathrm{H}$ stretching vibrations (top) of methylene groups and the surfactant concentrations (bottom): equilibrium HDTMA versus initial $\mathrm{CEC}_{\mathrm{in}}$
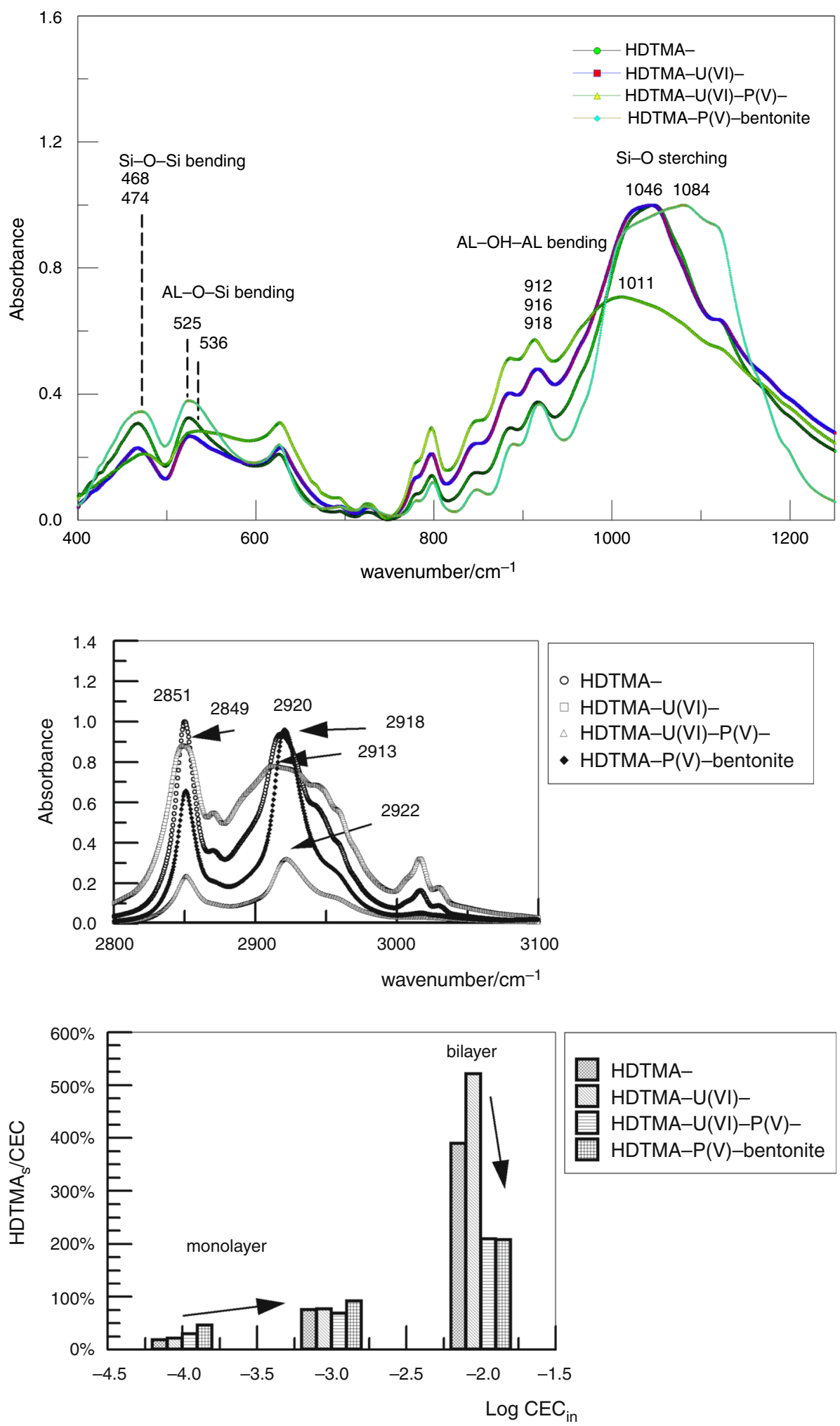

the U(VI) complex with the aluminosilicate matrix of the sorbent can be found in Fig. 3, where the $\mathrm{Si}-\mathrm{O}$ stretching vibration band locates at $1011 \mathrm{~cm}^{-1}$ for HDTMA-U(VI)$\mathrm{P}(\mathrm{V})$-bentonite. The less hydrated $\mathrm{U}(\mathrm{VI})$ phosphate complex interacts with oxygen atoms from $\mathrm{Si}-\mathrm{O}$ groups more strongly than the strongly hydrated $\mathrm{U}(\mathrm{VI})$ ions and the spaciously extended HDTMA $^{+}$cations (band at $1046 \mathrm{~cm}^{-1}$ ), which have a low ionic potential, and much 
more strongly than $\mathrm{P}(\mathrm{V})$ ions (band at $1084 \mathrm{~cm}^{-1}$ ), which probably only form hydrogen bonds with Al-OH groups, which are more reactive than $\mathrm{Si}-\mathrm{OH}$ groups.

The bands responsible for $\mathrm{C}-\mathrm{H}$ stretching vibrations in the methylene groups of the surfactant are found in the $2800-3100 \mathrm{~cm}^{-1}$ region (Fig. 4a). They are very sensitive to the arrangement of surfactant cations, i.e., to their trans (ordered) or gauche (chaotic) conformers [29]. For the initial concentrations of HDTMA in the aqueous phase of $10^{-4}$ and $10^{-3} \mathrm{~mol} \mathrm{dm}^{-3}$ (not shown in this figure), only minute changes in the positions of asymmetric and symmetric C-H vibrations are observed (from 2852 to 2854 and from 2925 to $2928 \mathrm{~cm}^{-1}$ ), which result from the formation of a monolayer of $\mathrm{HDTMA}^{+}$cations. The concentration of HDTMA in the sorbent phase is higher for HDTMA-U(VI)-P(V)- and HDTMA-P(V)-bentonite than for the remaining forms of this mineral, which means that phosphate ions interact with surfactant cations HDTMA ${ }^{+}$ probably via formation of ionic pairs (HDTMA) $2\left(\mathrm{HPO}_{4}\right)$. The most interesting results are observed for the highest HDTMA concentration, i.e., $10^{-2} \mathrm{~mol} \mathrm{dm}^{-3}$ (Fig. 4a). There is an evident shift of the $\mathrm{C}-\mathrm{H}$ vibration band from 2922 to $2913 \mathrm{~cm}^{-1}$ when HDTMA-U(VI)-P(V)-bentonite is compared with HDTMA-U(VI)-bentonite. The double layer of surfactant cations at this concentration of HDTMA-Br [6] is decomposed upon the influence of $\mathrm{P}(\mathrm{V})$ ions, and as a consequence, the concentration of HDTMA in the sorbent phase decreases (Fig. 4b).

To summarize, the following reactions probably characterize the interaction of phosphate ions with surfactant cations, depending on the initial concentration of the surfactant:

$$
\begin{aligned}
& 2 \mathrm{HDTMA}^{+}+\mathrm{HPO}_{4}^{2-} \rightarrow\left(\mathrm{HDTMA}_{2}\left(\mathrm{HPO}_{4}\right) \downarrow ;\right. \\
& {[\mathrm{HDTMABr}]=10^{-4}-10^{-3} \mathrm{~mol} \mathrm{dm}^{-3}} \\
& S-(\mathrm{HDTMA})_{2}\left(1 / 2 \mathrm{HPO}_{4}\right) \rightarrow \mathrm{S}-\left(\mathrm{HDTMA}_{2}^{+}+1 / 2 \mathrm{HPO}_{4}^{2-}\right. \\
& {[\mathrm{HDTMABr}]=10^{-2} \mathrm{~mol} \mathrm{dm}^{-3},}
\end{aligned}
$$

where $S$ refers to the sorbent surface.

\section{TG-DSC-QMS analysis}

Figure 5 presents the TG, DSC and DTG curves of initial $\mathrm{Na}$-bentonite. In the case of unmodified $\mathrm{Na}$-bentonite, two endothermic peaks are observed. The first peak representing a mass loss of $0.79 \%$, with a minimum at about $83{ }^{\circ} \mathrm{C}$, is due to the removal of adsorbed and interlayer water [21]. In the second stage $\left(400-750{ }^{\circ} \mathrm{C}\right.$, a minimum at $672.7{ }^{\circ} \mathrm{C}$ ), the mass loss of $4.4 \%$ corresponds to dehydroxylation of the clay [30-33].

TG, DSC and DTG curves of bentonite samples for three different HDTMA-Br concentrations (used for loading the sorbent phase) are given in Figs. 6-8. Essentially, four regions in the DTG spectra are visible for $10^{-4} \mathrm{~mol} \mathrm{dm}^{-3}$ HDTMA-Br (the surfactant concentration in the clay, 18.8-46.1\% CEC): 50-150 (I), 200-400 (II), 350-550 (III) and $550-750{ }^{\circ} \mathrm{C}$ (IV). In region $\mathrm{I}$, there occurs an endothermic dehydration reaction. For HDTMA-bentonite and HDTMA-P(V)-bentonite, the temperatures of dehydration are lower than for HDTMA-U(VI)- and HDTMA$\mathrm{U}(\mathrm{VI})-\mathrm{P}(\mathrm{V})$-bentonite, which can be explained by the strong hydration of $\mathrm{U}(\mathrm{VI})$ ions. In region II, the peaks (minima) for HDTMA-U(VI)-P(V)-bentonite and HDTMA-P(V)-bentonite are shifted toward higher

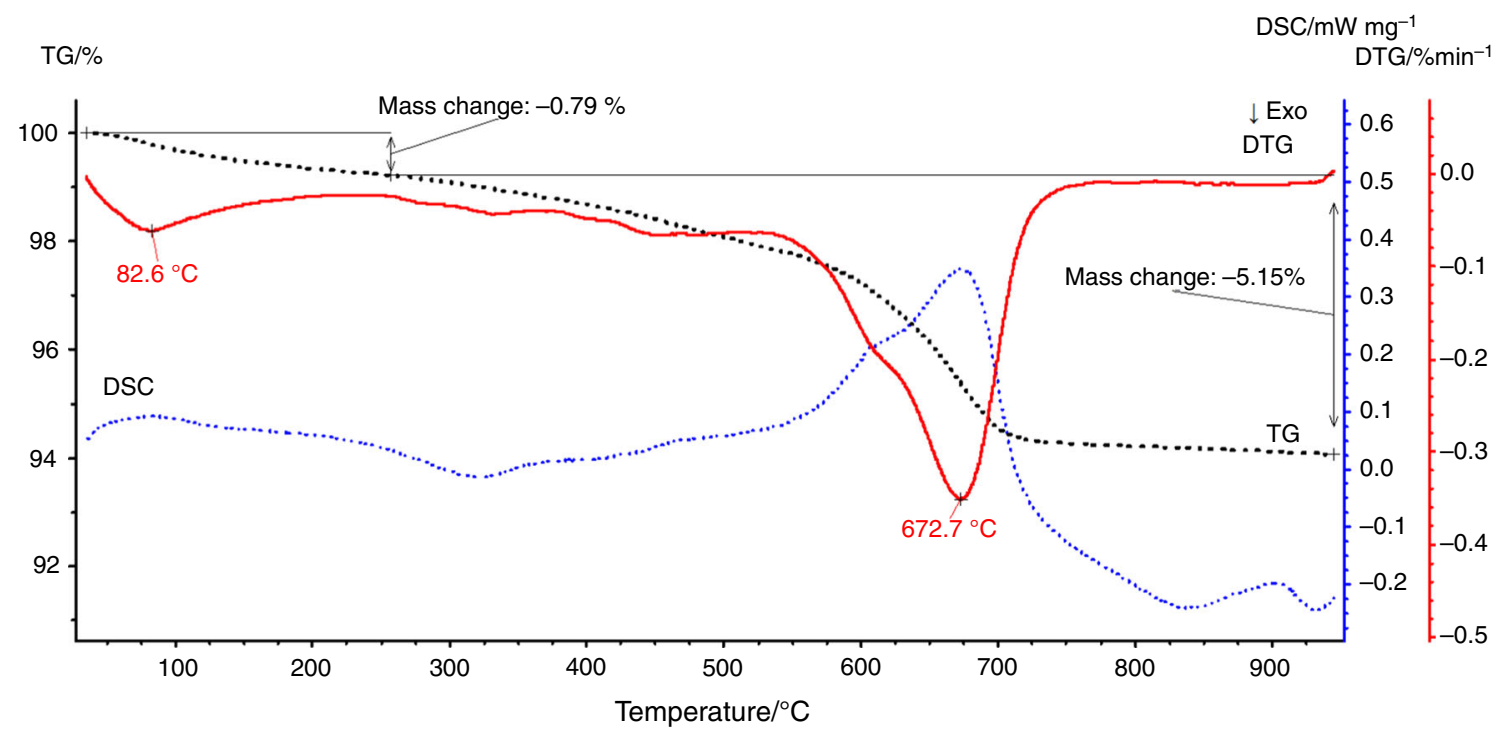

Fig. 5 TG, DTG and DSC curves of Na-bentonite 
$\mathrm{TG} / \%$

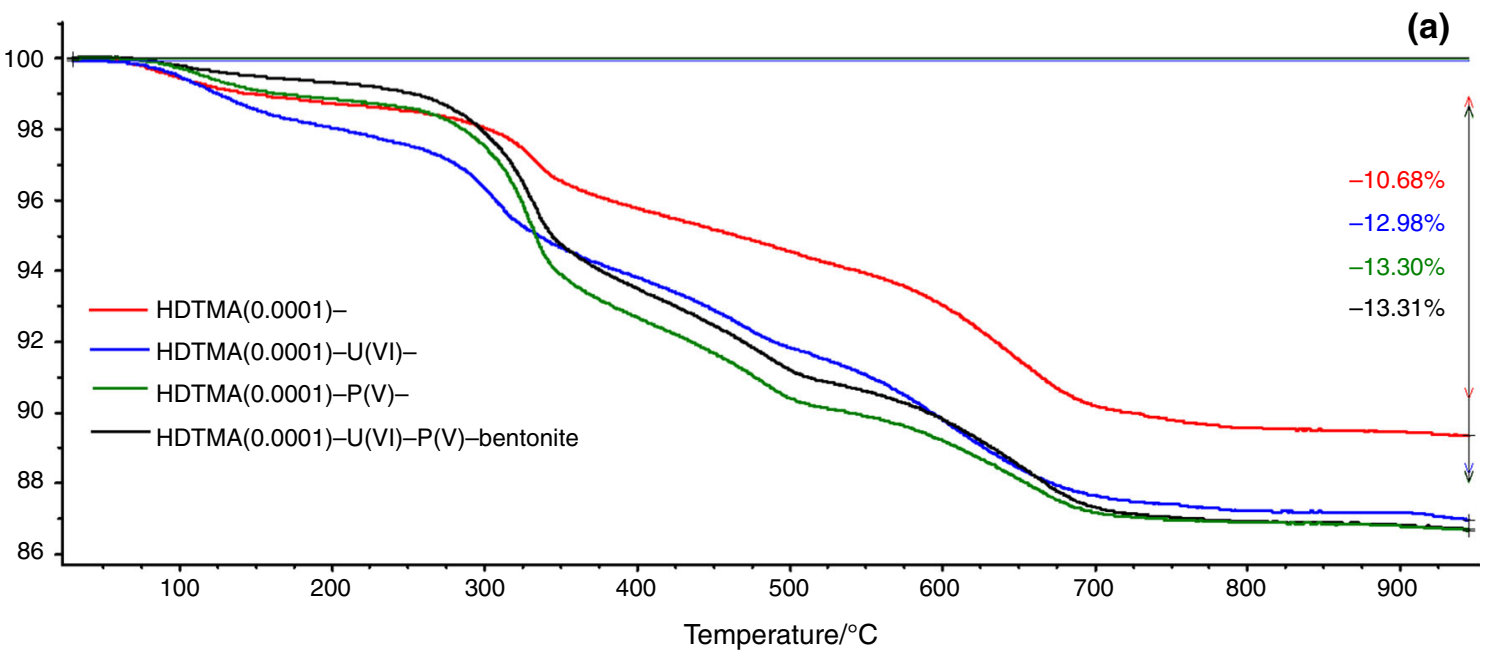

TG/\%

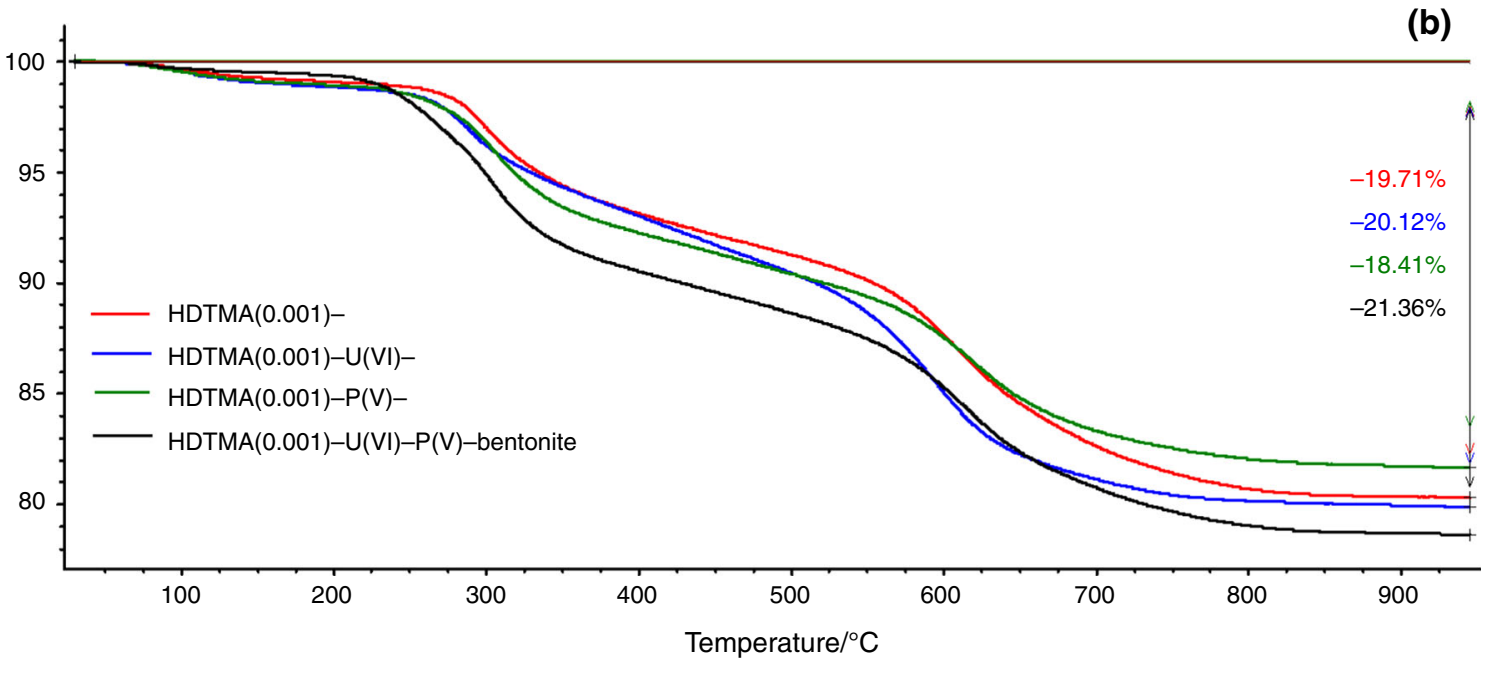

$\mathrm{TG} / \%$

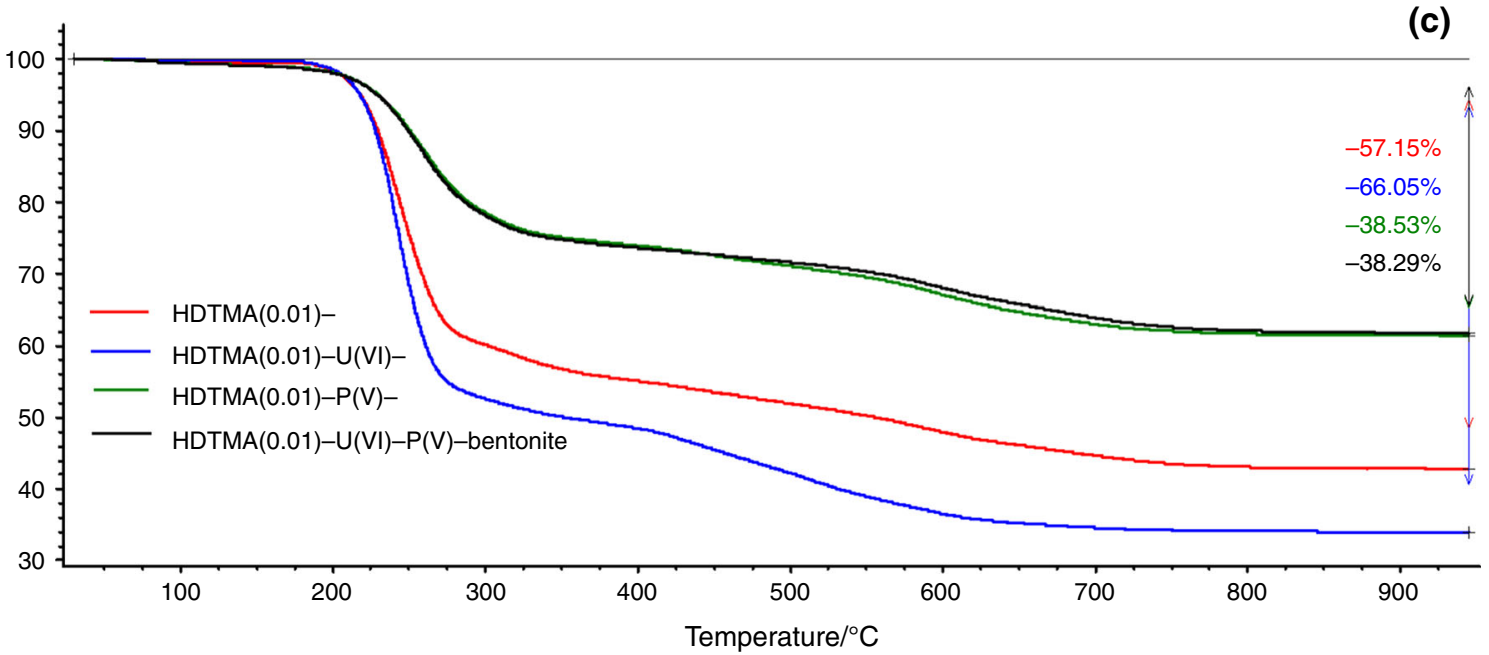

Fig. 6 TG curves of HDTMA-bentonite (red line), HDTMA-U(VI)bentonite (blue line), HDTMA-P(V)-bentonite (green line), HDTMA-U(VI)-P(V)-bentonite (black line) for different the initial concentrations of HDTMA: a $0.0001 \mathrm{~mol} \mathrm{dm}^{-3} ; \mathbf{b} 0.001 \mathrm{~mol} \mathrm{dm}^{-3}$; c $0.01 \mathrm{~mol} \mathrm{dm}^{-3}$. (Color figure online) 
temperatures, compared with HDTMA-U(VI)-bentonite, which can be the consequence of hindered exothermic defragmentation and oxidation of surfactant cations when phosphate ions interact with $\mathrm{HDTMA}^{+}$cations. It is interesting that the degradation of HDTMA-U(VI)-bentonite is easier than that of HDTMA-bentonite, which may be a result of the exchange reaction $\mathrm{UO}_{2}^{2+} / \mathrm{HDTMA}^{+}$, i.e., elimination of surfactant cations from the structure of the aluminosilicate by uranyl ions. In region III, the mass loss and heat flow (DSC spectrum, Fig. 8a) result probably from further oxidation of surfactant cations bound via electrostatic forces with the negatively charged aluminosilicate framework. Bands appearing in region IV correspond to the dehydroxylation of the mineral. The temperature of the dehydroxylation is lower for HDTMAU(VI)-bentonite than for Na-bentonite, 602.8 vs $672.7^{\circ} \mathrm{C}$. The surfactant cations and $\mathrm{U}(\mathrm{VI})$ ions expand the bentonite framework, though in the presence of $\mathrm{P}(\mathrm{V})$ ions this action is weakened due to the probable interaction of $\mathrm{U}(\mathrm{VI})$ ions with phosphate ions. The total reaction is endothermic.

Three regions in the DTG (Fig. 7b) and DSC (Fig. 8b) curves are observed at the initial concentration of $10^{-3}$ mol dm ${ }^{-3}$ HDTMA-Br (the surfactant concentration in the clay, $75.7-91.9 \%$ CEC). Region I corresponds to endothermic dehydration, and region II represents defragmentation/oxidation of surfactant cations. The peaks referring to region II are located at lower temperatures when compared with those for $10^{-4} \mathrm{~mol} \mathrm{dm}^{-3}$ HDTMA$\mathrm{Br}$, which is a consequence of partially physical and partially chemical sorption of the surfactant, i.e., sorption via exchange of $\mathrm{HDTMA}^{+}$with $\mathrm{Na}^{+}$cations and via Van der Waals interaction between alkyl chains of surfactant cations. Similarly to the case of $10^{-4} \mathrm{~mol} \mathrm{dm}^{-3}$ HDTMA$\mathrm{Br}$, phosphate ions suppress the oxidation of HDTMA-Br, which manifests as a shift of peaks from region II to higher temperatures, i.e., from 288.6 and 300.9 (HDTMA-U(VI)-, HDTMA-bentonite) to 305 and $303.7{ }^{\circ} \mathrm{C}$ (HDTMA-P(V)-, HDTMA-U(VI)-P(V)-bentonite). The bands in region III reflect the processes of dehydroxylation of the mineral and oxidation of charcoal. The exothermic process of oxidation prevails over dehydroxylation for HDTMA-, HDTMAU(VI)-, HDTMA-U(VI)-P(V)- and HDTMA-P(V)-bentonites, although it proceeds less efficiently for the last two forms of the sorbent.

For the concentration of $10^{-2}$ mol dm ${ }^{-3}$ HDTMA-Br (the concentration of surfactant in the clay $389.9-521.5 \%$ CEC), very sharp bands are observed in region I of the DTG profile (Fig. 7c). These bands, appearing in the temperature range of $249.5-242.8^{\circ} \mathrm{C}$, are characteristic of defragmentation/oxidation of surfactant cations, which form different arrangements [34, 35], i.e., monolayers, bilayers and micelles, and are bound-predominantly via Van der Waals forces-with the surface of the mineral and with each other. Phosphate ions suppress the oxidation of surfactant cations, which results in a shift of peaks 242.8 and 244.8 to 257.9 and $259.5{ }^{\circ} \mathrm{C}$. Small bands are visible in region II, which correspond to dehydroxylation of the mineral, commonly accompanied by oxidation of charcoal. The temperature of the peak minimum is the lowest for HDTMA-U(VI)-bentonite $\left(511^{\circ} \mathrm{C}\right)$, which is a consequence of the expansion of the aluminosilicate framework by U(VI) ions and the resultant easy disconnection of hydroxyl groups from the structural skeleton of the bentonite.

The DSC spectrum of HDTMA- (red curve, Fig. 8c) and HDTMA-U(VI)-bentonite (blue curve, Fig. 8c) shows a very complicated pattern with many peaks. The most interesting one is the endothermic peak in the region of $80-150^{\circ} \mathrm{C}$, probably resulting from a phase change of solid HDTMA-Br, i.e., the formation of a gauche disordered conformation of surfactant cations [36-38].

Summarizing the evaluation of the thermal stability of HDTMA-bentonites, one can conclude that, first and foremost, it depends on whether the concentration of surfactant cations is below or above the cation exchange capacity of the sorbent. In the former case, the high temperatures of surfactant oxidation and mineral dehydroxylation result from the ionic interaction between the sorbent and surfactant forming monolayers in the interior of the sorbent structure, whereas in the latter case these evidently lower temperatures are a reflection of predominantly physical sorption of surfactant forming bilayers in the interior and on the surface of the mineral $[18,39,40]$. It is of course difficult to determine accurately the concentrations of the surfactant characteristic of its purely electrostatic interaction with the aluminosilicate skeleton, since the registered mass losses refer not only to the oxidation of surfactant, but also to the burning of charcoal, a residue product of incomplete oxidation.

The main components appearing in the spectra are $\mathrm{CO}$, $\mathrm{CO}_{2}, \mathrm{H}_{2} \mathrm{O}, \mathrm{NO}$ and $\mathrm{NO}_{2}$. Their presence is the consequence of surfactant oxidation. Less pronounced are the components originating from surfactant decomposition, i.e., peaks characteristic of alkanes, alkenes and amines.

Examples of MS spectra are shown in Figs. 9 and 10. Two facts are unquestionable: Surfactant oxidation occurs in two stages, and the decrease in the temperature of decomposition is accompanied by an increase in surfactant concentration. The peaks characteristic of $\mathrm{CO}, \mathrm{CO}_{2}, \mathrm{H}_{2} \mathrm{O}$, $\mathrm{NO}, \mathrm{NO}_{2}$, given in Fig. 9, appears in the $200-400$ and $600-800{ }^{\circ} \mathrm{C}$ regions. This is the consequence of the stepwise oxidation of surfactant cations, which proceeds easily for the cations bound to the surface of the sorbent by nonelectrostatic forces, and less easily for surfactant cations hidden in the pores of the mineral and interacting with the aluminosilicate skeleton via electrostatic forces. 

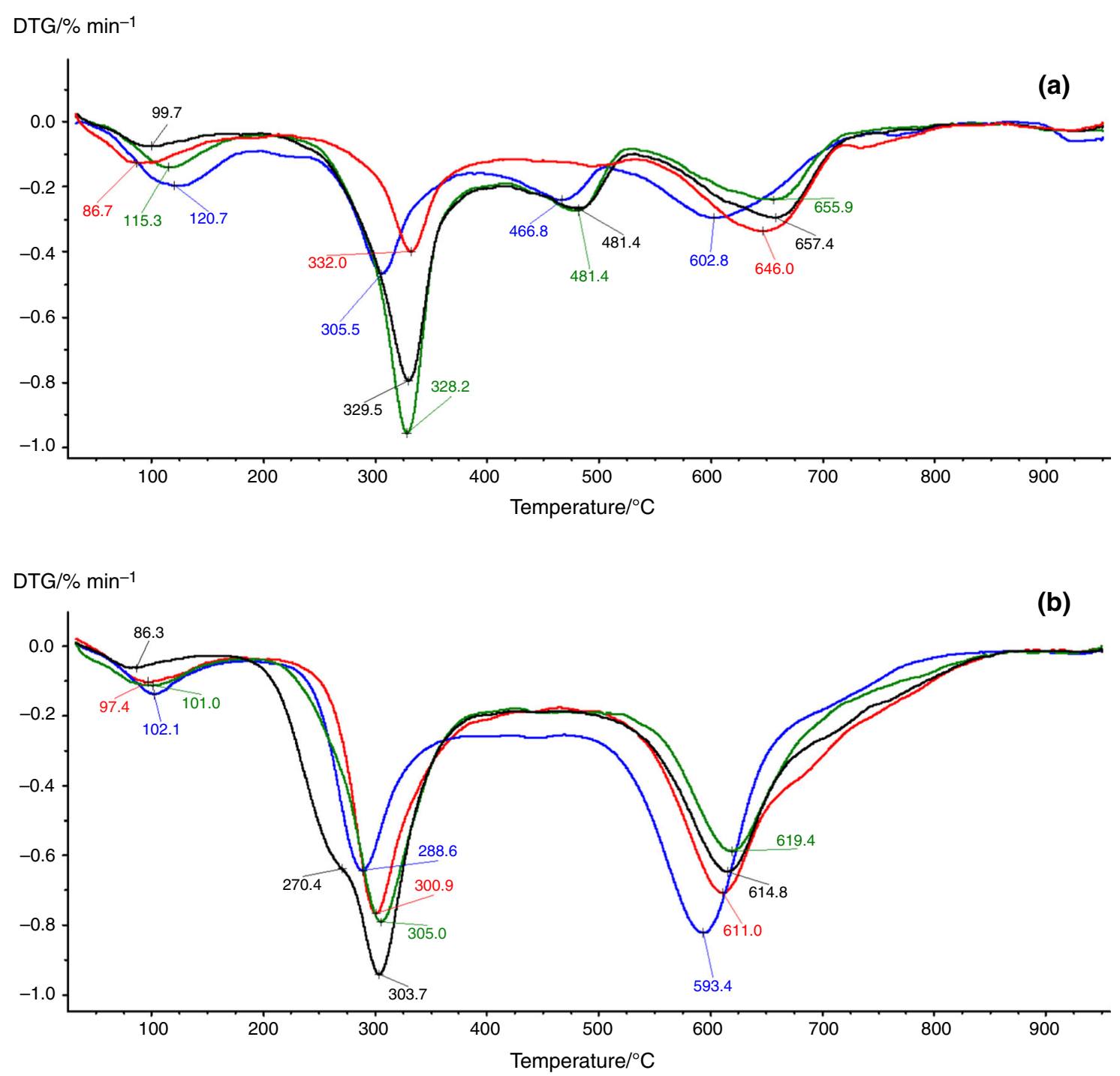

$\mathrm{DTG} / \% \min ^{-1}$

(c)

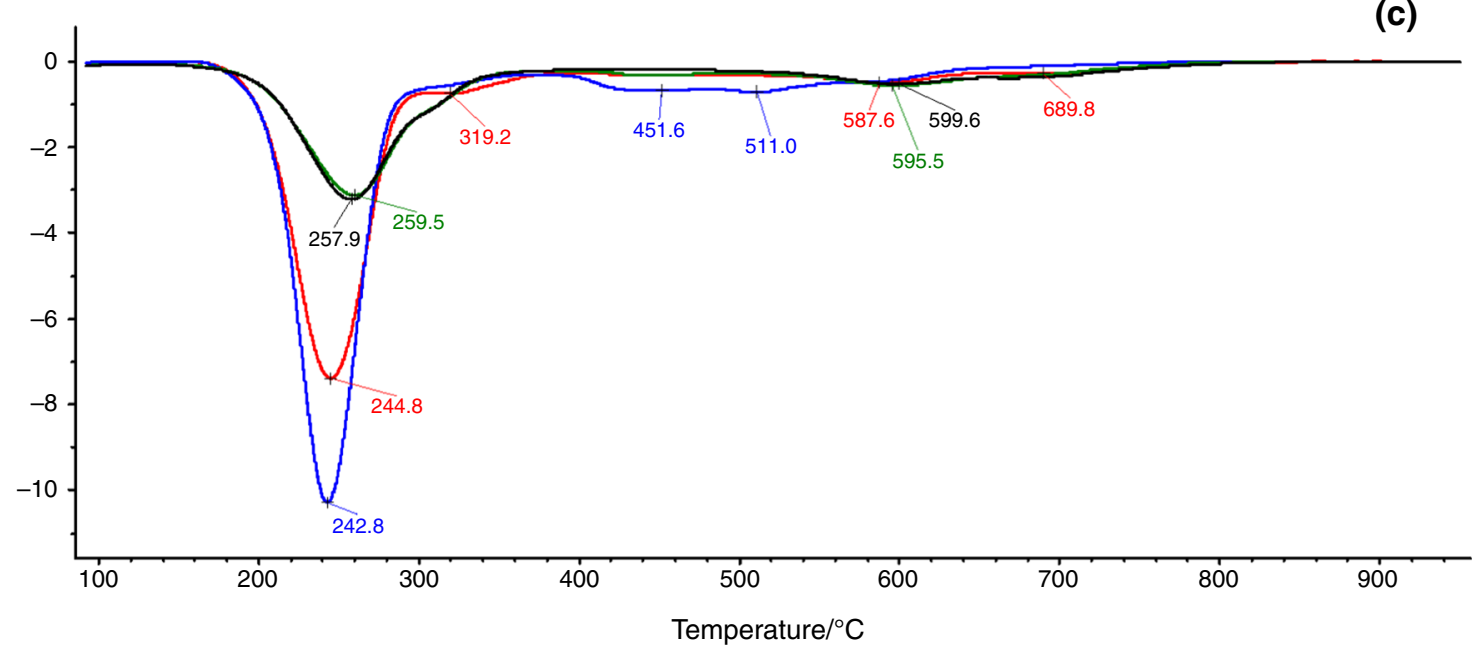

Fig. 7 DTG curves of HDTMA-bentonite (red line), HDTMA$\mathrm{U}(\mathrm{VI})$-bentonite (blue line), HDTMA-P(V)-bentonite (green line), HDTMA-U(VI)-P(V)-bentonite (black line) for different the initial concentrations of HDTMA: a $0.0001 \mathrm{~mol} \mathrm{dm}^{-3} ; \mathbf{b} 0.001 \mathrm{~mol} \mathrm{dm}^{-3}$; c $0.01 \mathrm{~mol} \mathrm{dm}^{-3}$. (Color figure online) 
$\mathrm{DSC} / \mathrm{mW} \mathrm{mg}^{-1}$

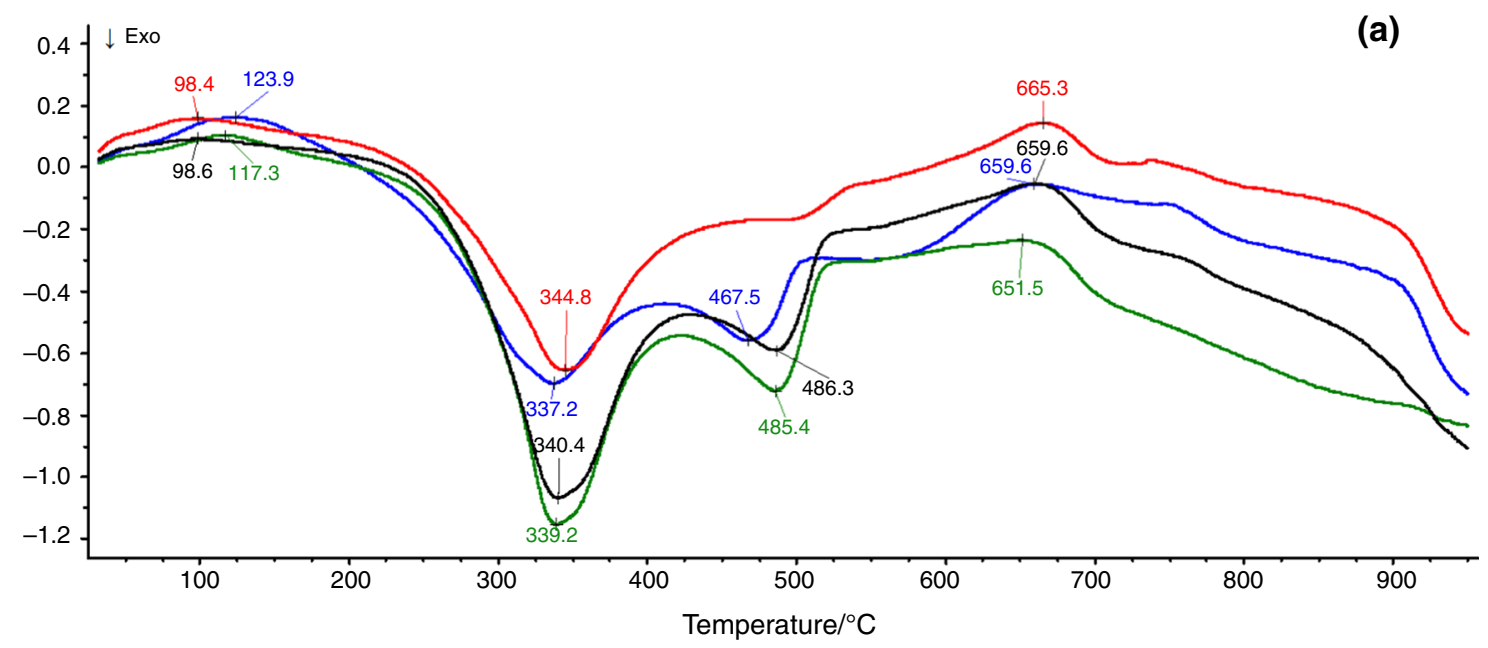

$\mathrm{DSC} / \mathrm{mW} \mathrm{mg}^{-1}$

(b)

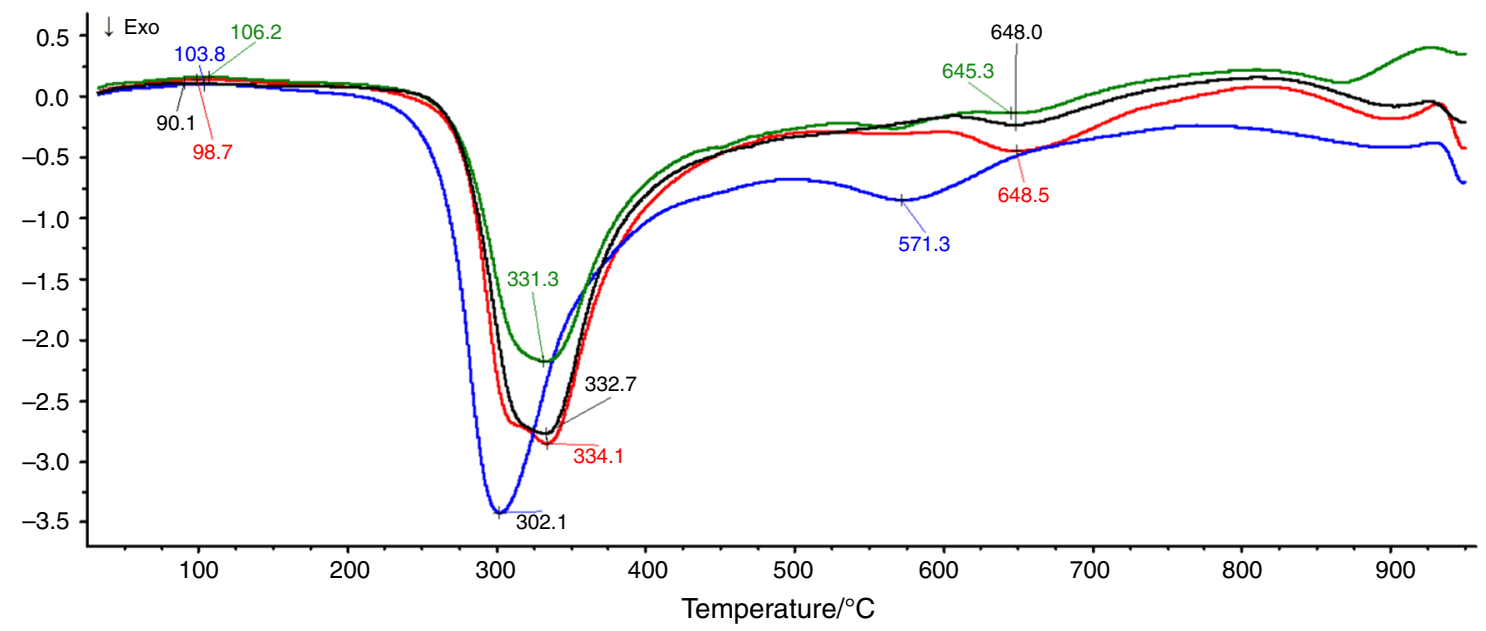

$\mathrm{DSC} / \mathrm{mW} \mathrm{mg}^{-1}$

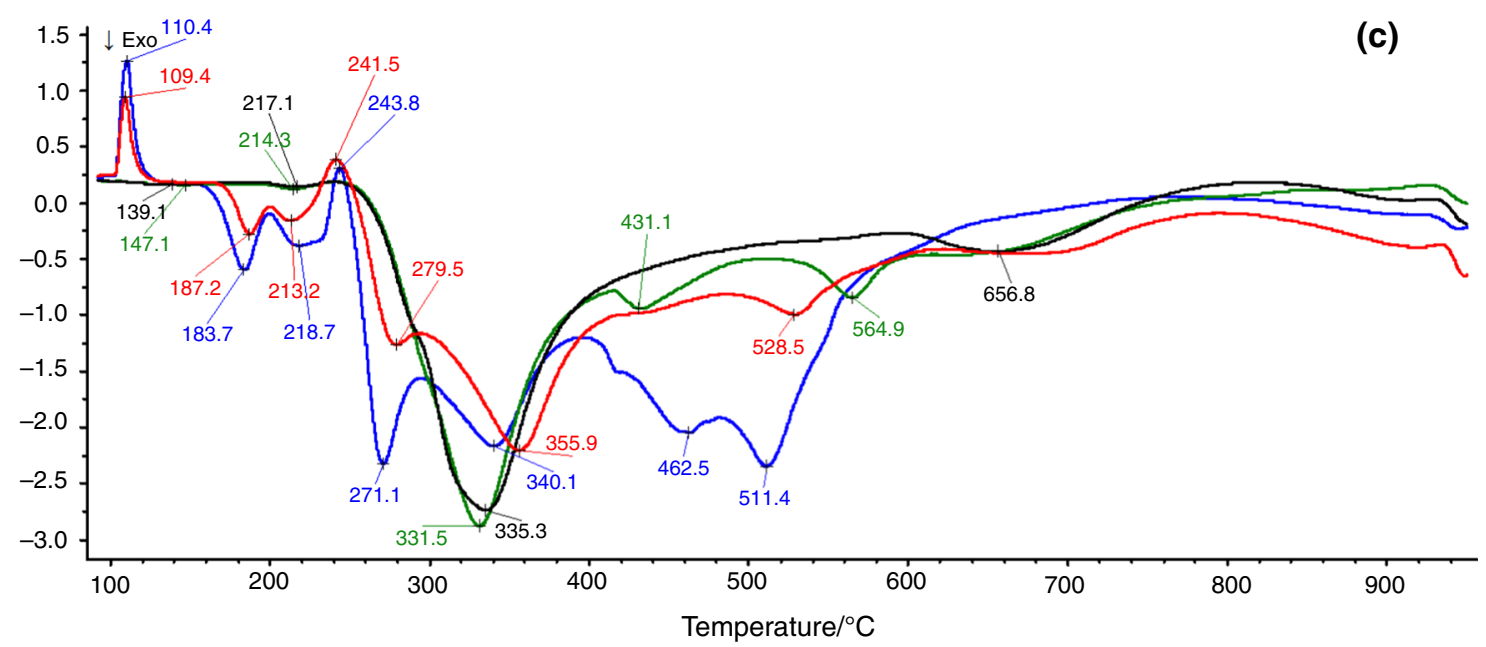

Fig. 8 DSC curves of HDTMA-bentonite (red line), HDTMA$\mathrm{U}(\mathrm{VI})-$ bentonite (blue line), HDTMA-P(V)-bentonite (green line), HDTMA-U(VI)-P(V)-bentonite (black line) for different the initial concentrations of HDTMA: a $0.0001 \mathrm{~mol} \mathrm{dm}^{-3} ; \mathbf{b} 0.001 \mathrm{~mol} \mathrm{dm}^{-3}$; c $0.01 \mathrm{~mol} \mathrm{dm}^{-3}$. (Color figure online) 
Fig. 9 MS profiles of gaseous products of defragmentation [15 $\left(\mathrm{CH}_{3}\right) ; 43$ (amine); $\left.58\left(\mathrm{NCH}_{2}\left(\mathrm{CH}_{3}\right)_{2}\right) ; 94\left(\mathrm{CH}_{3} \mathrm{Br}\right)\right]$ and oxidation $\left[18\left(\mathrm{H}_{2} \mathrm{O}\right) ; 30\right.$ (NO); $\left.44\left(\mathrm{CO}_{2}\right) ; 46\left(\mathrm{NO}_{2}\right)\right]$ characteristic for organobentonite decomposition vs temperature for samples: $\operatorname{HDTMA}(0.0001)-($ red line $)$, $\operatorname{HDTMA}(0.001)-($ blue line), HDTMA(0.01)-bentonite (black line). (Color figure online)

Fig. 10 MS profiles of gaseous products of defragmentation [15 $\left(\mathrm{CH}_{3}\right) ; 43$ (amine); 58 $\left.\left(\mathrm{NCH}_{2}\left(\mathrm{CH}_{3}\right)_{2}\right) ; 94\left(\mathrm{CH}_{3} \mathrm{Br}\right)\right]$ and oxidation $\left[18\left(\mathrm{H}_{2} \mathrm{O}\right) ; 30\right.$ (NO); $\left.44\left(\mathrm{CO}_{2}\right) ; 46\left(\mathrm{NO}_{2}\right)\right]$ characteristic for organobentonite decomposition vs temperature for samples: HDTMA(0.0001)-U(VI)-P(V)(red line), HDTMA(0.001)$\mathrm{U}(\mathrm{VI})-\mathrm{P}(\mathrm{V})-$ (blue line), $\operatorname{HDTMA}(0.01)-\mathrm{U}(\mathrm{VI})-\mathrm{P}(\mathrm{V})-$ bentonite (black line). (Color figure online)
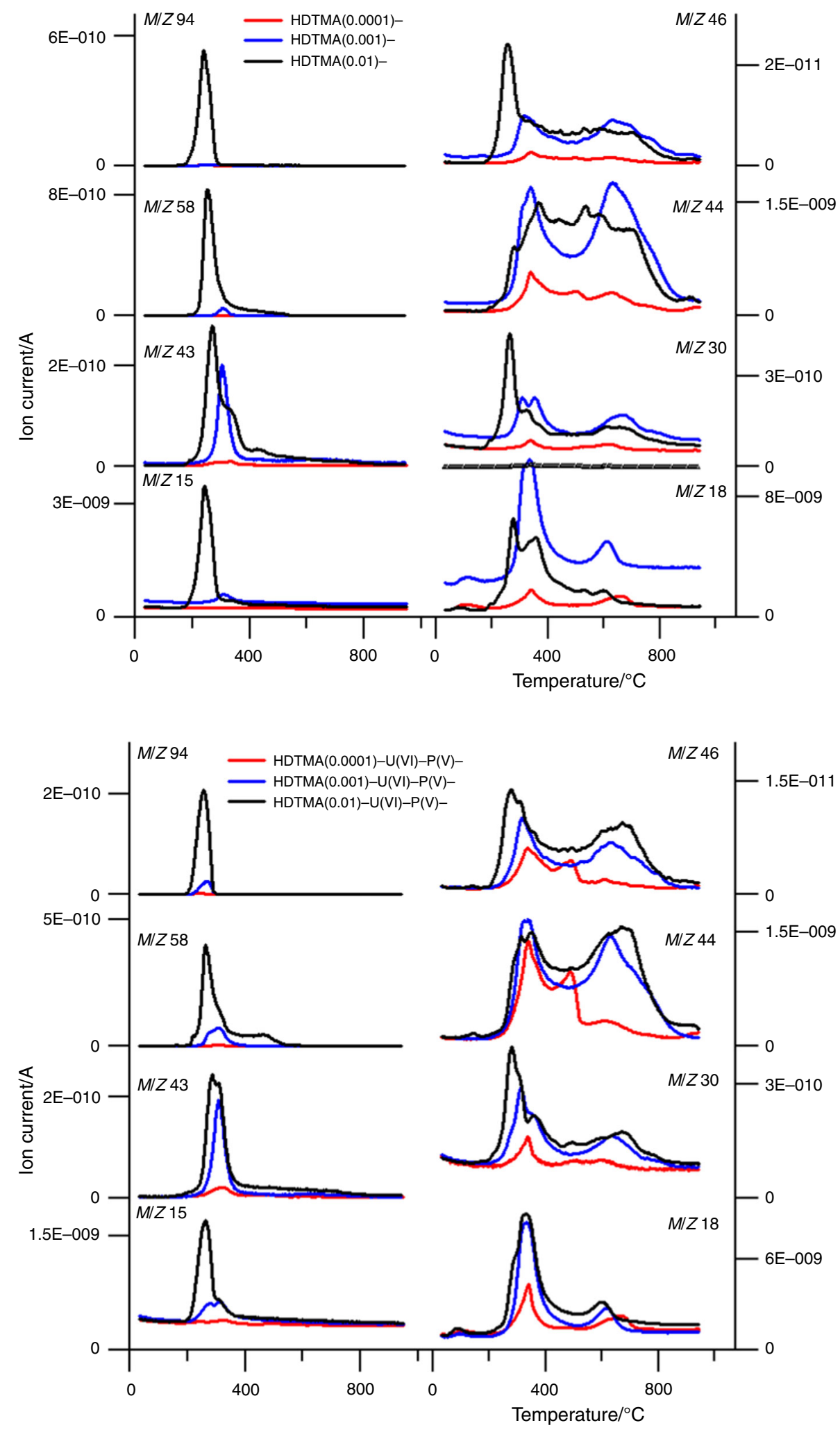

The decomposition of the surfactant follows a Hoffman elimination reaction [17, 41, 42] (with the formation of alkenes and ammonia). The presence of oxygen initializes the scission of $\mathrm{C}-\mathrm{H}$ bonds in alkanes, "departure" of hydrogen atoms from the alkane structure and formation of alkenes, which are then rearranged into aromatic compounds and charcoal. The decrease in the temperature of decomposition of the surfactant along with its concentration is prominent in 
the spectra characteristic of methane, acetaldehyde, alkylamines and methyl bromide. The presence of methyl bromide, confirmed by the presence of a $1750 \mathrm{~cm}^{-1}$ band in the FTIR spectrum of gaseous products, attests to the partial participation of the nucleophilic substitution mechanism $S_{\mathrm{N}}^{2}$ in the thermal decomposition of the surfactant.

The excess of the surfactant is bound by Van der Waals forces to the part of the surfactant which is "attached" to the aluminosilicate skeleton via electrostatic forces, which is why defragmentation of alkylammonium cations proceeds more easily for the higher concentrations of the surfactant (Fig. 10, the peaks characteristic of $\mathrm{CH}_{3}(M / Z=15)$, $\mathrm{NCH}_{2}\left(\mathrm{CH}_{3}\right)_{2}(M / Z=58)$ and $\mathrm{CH}_{3} \mathrm{Br}(M / Z=94)$, at which surfactant cations form ordered arrangements known as "trans" conformers $[22,43]$. The increase in surfactant concentration also results in a decrease in the number of water molecules in the interlayer space of the mineral; what remains is the weakly adsorbed water on the external surface of the sorbent which causes a shift in the temperature of water release toward lower values.

\section{Conclusions}

1. The sorption of U(VI) on HDTMA-bentonite in the presence of phosphates is an effective method of U(VI) elimination from the aqueous phase

2. The sorption is, in some part, irreversible, which is the consequence of the contribution of precipitation and surface complexation of $\mathrm{U}(\mathrm{VI})$ to the overall process of immobilization of $\mathrm{U}(\mathrm{VI})$ on bentonite.

3. The thermal degradation of the surfactant sorbed on bentonite proceeds in two stages: at $300-400$ and at 600-800 ${ }^{\circ} \mathrm{C}$ with the emission of $\mathrm{CO}, \mathrm{CO}_{2}, \mathrm{H}_{2} \mathrm{O}$, NO and $\mathrm{NO}_{2}$. The first stage involves defragmentation and oxidation of surfactant cations present in the interior and on the surface of the mineral. The second stage involves oxidation of charcoal and simultaneous dehydroxylation of the sorbent. The oxidation of surfactant cations and the dehydroxylation of the mineral proceed with more difficulty in the presence of phosphates.

4. FTIR spectra of the sorption products show that the $\mathrm{U}(\mathrm{VI})$ phosphate complex and phosphate ions interact with the aluminosilicate framework, i.e., $\mathrm{Si}-\mathrm{O}-\mathrm{Si}, \mathrm{Al}-$ $\mathrm{OH}$ groups.

Open Access This article is distributed under the terms of the Creative Commons Attribution 4.0 International License (http://crea tivecommons.org/licenses/by/4.0/), which permits unrestricted use, distribution, and reproduction in any medium, provided you give appropriate credit to the original author(s) and the source, provide a link to the Creative Commons license, and indicate if changes were made.

\section{References}

1. Kausar A, Bhatti HN. Adsorptive removal of uranium from wastewater: a review. J Chem Soc Pak. 2013;35(3):1041-52.

2. Gao M, Zhu G, Gao C. A review: adsorption materials for the removal and recovery of uranium from aqueous solutions. Energy Environ Focus. 2014;3:219-26.

3. Konstantinou M, Demetriou A. Adsorption of hexavalent uranium on dunite. Glob NEST J. 2007;9(3):229-36.

4. Sellin $P$, Leupin OX. The use of clay as an engineered barrier in radioactive-waste management $-\mathrm{a}$ review. Clays Clay Miner. 2013;61(6):477-98.

5. Majdan M, Pikus S, Gajowiak A, Sternik D, Zięba E. Uranium sorption on bentonite modified by octadecyltrimethylammonium bromide. J Hazard Mater. 2010;184(1-3):662-7.

6. Majdan M, Pikus S, Gajowiak A, Gładysz-Płaska A, Krzyżanowska $\mathrm{H}$, Żuk J, Bujacka M. Characterization of uranium(VI) sorption by organobentonite. Appl Surf Sci. 2010;256(17):5416-21.

7. Bickford J, Foote M, Taylor P. Sorbents testing for the solidification of organic process wastestreams from the Radiochemical Engineering Development Center at Oak Ridge National Laboratory, WM2008 Conference, February 24-28, 2008, Phoenix, AZ, Abstract 8114. http://www.wmsym.org/archives/2008/pdfs/ 8114.pdf.

8. Bachmaf S, Planer-Friedrich B, Merkel BJ. Effect of sulfate, carbonate, and phosphate on the uranium(VI) sorption behavior onto bentonite. Radiochim Acta. 2008;96(6):359-66.

9. Grabias E, Gładysz-Płaska A, Lipke A, Pikus S, Majdan M. Application of the de Job method in the evaluation of the stoichiometry of uranyl phosphate complexes sorbed on bentonite. Eur J Chem. 2016;7(1):42-8.

10. Erdem B, Özcan AS, Özcan A. Preparation of HDTMA-bentonite: characterization studies and its adsorption behavior toward dibenzofuran. Surf Interface Anal. 2010;42:1351-6.

11. Ikhtiyarova GA, Özcan AS, Gök Ö, Özcan A. Characterization of natural- and organo-bentonite by XRD, SEM, FT-IR and thermal analysis techniques and its adsorption behaviour in aqueous solutions. Clay Miner. 2012;47(1):31-44.

12. Dweck J, Barreto EP, Meth S, Büchler PM. Partially exchanged organophilic bentonites Part I. characterization by thermal analysis on calcined mass basis. $\mathrm{J}$ Therm Anal Calorim. 2011;105:907-13.

13. Vianna MMGR, Valenzuela-Diaz FR, Kozievitch VFJ, Dweck J, Büchler PM. Synthesis and characterization of modified clays as sorbents of toluene and xylene. https://www.ipen.br/biblioteca/ cd/ptech/2003/PDF/22_06.pdf.

14. Nuntiya A, Sompech S, Aukkaravittayapun S, Pumchusak J. The effect of surfactant concentration on the interlayer structure of organoclay. Chiang Mai J Sci. 2008;35(1):199-205.

15. Sreedharan V, Sivapullaiah PV. Effect of organic modification on adsorption behaviour of bentonite. Indian Geotech $\mathrm{J}$. 2012;42(3):161-8.

16. El Messabeb-Ouali A, Benna-Zayani M, Ayadi-Trabelsi M, Sauvé S. Morphology, structure, thermal stability, XR-diffraction, and infrared study of hexadecyltrimethylammonium bromide-modified smectite. Int J Chem. 2013;5(2):12-28.

17. Kooli F. Effect of C16TMA contents on the thermal stability of organo-bentonites: in situ X-ray diffraction analysis. Thermochim Acta. 2013;551:7-13.

18. Park Y, Ayoko GA, Kristof J, Horváth E, Frost RL. A thermoanalytical assessment of an organoclay. J Therm Anal Calorim. 2012;107:1137-42.

19. Park Y, Frost RL, Ayoko GA, Morgan DL. Adsorption of p-nitrophenol on organoclays: a thermoanalytical study. J Therm Anal Calorim. 2013;111:41-7. 
20. Lapides I, Borisover M, Yariv S. Thermal analysis of hexadecyltrimethylammonium-montmorillonites, part 1. Thermogravimetry, carbon and hydrogen analysis and thermo-IR spectroscopy analysis. J Therm Anal Calorim. 2011;105:921-9.

21. Lapides I, Borisover M, Yariv S. Thermal analysis of hexadecyltrimethylammonium-montmorillonites: part 2. Thermo-XRDspectroscopy-analysis. J Therm Anal Calorim. 2011;105:39-51.

22. He H, Ding Z, Zhu J, Yuan P, Xi Y, Yang D, Frost RL. Thermal characterization of surfactant-modified montmorillonites. Clays Clay Miner. 2005;53(3):287-93.

23. Gajowiak A, Gładysz-Płaska A, Sternik D, Pikus S, Sabah E, Majdan M. Sorption of uranyl ions on organosepiolite. Chem Eng J. 2013;219:459-68.

24. Marczenko Z, Balcerzak M. Spektrofotometryczne metody w analizie chemicznej. Warszawa: Wydawnictwo Naukowe PWN; 1998.

25. Gales ME, Julian EC, Kroner RC. Method for quantitative determination of total phosphorus in water. Am Water Works Assoc J. 1965;58:1363-8.

26. Houhoune F, Nibou D, Chegrouche S, Menacer S. Behaviour of modified hexadecyltrimethylammonium bromide bentonite toward uranium species. J. Environ Chem Eng. 2016;4:3459-67.

27. Pabalan RT, Turner DR. Uranium(6+) sorption on montmorillonite: experimental and surface complexation modeling study. Aquat Geochem. 1997;2:203-26.

28. Kang MJ, Han BE, Hahn PS. Precipitation and adsorption of uranium(VI) under various aqueous conditions. Environ Eng Res. 2002;7(3):149-57.

29. Rožić M, Miljanić S. Sorption of HDTMA cations on Croatian natural mordenite tuff. J Hazard Mater. 2011;185:423-9.

30. Önal M, Sarikaya Y. Thermal behavior of a bentonite. J Therm Anal Calorim. 2007;90(1):167-72.

31. Dweck J. Qualitative and quantitative characterization of Brazilian natural and organophilic clays by thermal analysis. J Therm Anal Calorim. 2008;92:129-35.

32. Sternik D, Majdan M, Deryło-Marczewska A, Żukociński G, Gładysz-Płaska A, Gun'ko VM, Mikhalovsky SV. Influence of Basic Red 1 dye adsorption on thermal stability of Na-clinoptilolite and Na-bentonite. J Therm Anal Calorim. 2011;103:607-15.
33. Zhang Y, Liu Q, Wu Z, Zhang Y. Thermal behavior analysis of two bentonite samples selected from China. J Therm Anal Calorim. 2015;121:1287-95.

34. de Paiva LB, Morales AR, Valenzuela Díaz FR. Organoclays: properties, preparation and applications. Appl Clay Sci. 2008;42:8-24.

35. He H, Frost RL, Bostrom T, Yuan P, Duong L, Yang D, Xi Y, Kloprogge JT. Changes in the morphology of organoclays with HDTMA + surfactant loading. Appl Clay Sci. 2006;31:262-71.

36. Zhou Q, Frost RL, He H, Xi Y, Zbik MJ. TEM, XRD, and thermal stability of adsorbed paranitrophenol on DDOAB organoclay. J Colloid Interface Sci. 2007;311:24-37.

37. Feng X, Hu G, Meng X, Ding Y, Zhang S, Yang M. Influence of ethanol addition on the modification of montmorillonite by hexadecyltrimethylammonium bromide. Appl Clay Sci. 2009;45: 239-43.

38. Xu L, Zhu L. Structures of OTMA- and DODMA-bentonite and their sorption characteristics towards organic compounds. J Colloid Interface Sci. 2009;331:8-14.

39. Zhu J, He H, Guo J, Yang D, Xie X. Arrangement models of alkylammonium cations in the interlayer of $\mathrm{HDTMA}^{+}$pillared montmorillonites. Chin Sci Bull. 2003;48(4):368-72.

40. Bu H, Yuan P, Liu H, Liu D, Zhou X. Thermal decomposition of long-chain fatty acids and its derivative in the presence of montmorillonite: a thermogravimetric (TG/DTG) investigation. J Therm Anal Calorim. 2016. doi:10.1007/s10973-016-6022-5.

41. Xie W, Gao Z, Pan W, Hunter D, Singh A, Vaia R. Thermal degradation chemistry of alkyl quaternary ammonium montmorillonite. Chem Mater. 2001;13:2979-90.

42. Bellucci F, Camino G, Frache A, Sarra A. Catalytic charringvolatilization competition in organoclay nanocomposites. Polym Degrad Stab. 2007;92:425-36.

43. Majdan M, Pikus S, Rzączyńska Z, Iwan M, Maryuk O, Kwiatkowski R, Skrzypek H. Characteristics of chabazite modified by hexadecyltrimethylammonium bromide and of its affinity toward chromates. J Mol Struct. 2006;791:53-60. 